\title{
Reconhecimento tenso, acontecimento inaugural: na direção de outra comunicação ${ }^{1}$
}

Jose Luiz Aidar Prado

\section{Resumo}

A partir de uma teoria do acontecimento, buscamos pensar a comunicação como circulação de marcas em um campo tensivo, afetivamente investido, em que os sujeitos emergem ao serem fiéis ao processo de verdade instaurado com 0 acontecimento. A tensividade é pensada com Zilberberg, a teoria do acontecimento com Badiou, a formação do sujeito - submetido ao poder, mas capaz de agência -, com Butler e Safatle, que, por sua vez, propõe o desamparo como afeto fundamental. A comunicação se coloca, portanto, a partir da teoria do acontecimento, com cunho político, capaz de tematizar a transformação do circuito dos afetos e, em consequência, a emergência de novas sociabilidades.

\section{Palavras-Chave}

Teoria do acontecimento. Afeto. Política.

José Luiz Aidar Prado | aidarprado@gmail.com Doutor em Comunicação e Semiótica pela Pontifícia Universidade Católica de São Paulo - PUC-SP, Brasil. Professor do Programa de Pós-Graduação em Comunicação e Semiótica da PUC-SP. Coordenador do Grupo de Pesquisas em Mídia e Discurso - Um dia sete dias. Autor dos livros Habermas com Lacan e Convocações biopolíticas nos dispositivos comunicacionais. Editor da revista Galáxia.
Tenho pensado os processos comunicacionais a partir das marcas e inscrições que circulam em um campo tensivo de sociabilidades (PRAD0, 2015, 2016), produzindo efeitos comunicacionais de informação, entendimento parcial nas interações, acordos normativos e trocas/diálogos. Nesse campo, as partes disputam os sentidos ao constituir discursos carregados de afetos e com variação de intensidades. Não se comunica apenas na elevada intensidade estésica, mas também na conversa trivial cotidiana. Não se trata de afirmar que a informação ou a comunicação cotidiana não constituem comunicação, porque estariam dominadas por um paradigma sistêmico, definindo-se idealizadamente uma comunicação (habermasiana) mais próxima da arte e do acontecimento. Se a comunicação é um conjunto de marcas e inscrições a circular em um campo tensivo, na medida em que os discursos disputam os sentidos ${ }^{2}$, tal disputa pode ir da estesia para a anestesia ou vice-versa, através de graus afetivos. Aqui, seguiremos a ideia de Zilberberg (2011) de que é a intensidade que promove a extensidade, ou seja, a criação de mundo brota no acontecimento (intensidade), cujos sentidos são disputados pelos 
discursos antagônicos na extensidade posterior (acontecimento tornado mundo, disputado pelos discursos concorrentes), no cotidiano pós-acontecimental. Em termos de valências ${ }^{3}$, o caminho semiótico vai progressivamente do assomo do acontecimento (intensidade), passando pela modulação, para chegar à resolução nos estados. Dito de outro modo, os sentidos se ancoram na afetividade (idem, p. 45), e a comunicação acompanha a distribuição de discursos afetados.

Nesse processo, o campo tensivo registra afetivamente os devires, para os quais se pode investigar a amplitude, a velocidade e a duração.

Como diz Zilberberg: "a questão é discernir (...) de que modo um gerúndio, vinculado ao acontecimento, converte-se em particípio, vinculado ao estado" (idem, p.23). 0 caminho do acontecimento ao estado é o da descendência, pois vai da brutalidade do acontecimento, que irrompe em uma estesia que os discursos em um primeiro momento não conseguem concernir, até a permanência, em que se dá a estabilidade de um diálogo menos ou mais difícil, a depender de como os antagonismos se enfrentam. As ações comunicativas dão-se a partir do acontecimento, quando os discursos passam a disputar os sentidos produzidos a partir dele. Há sujeitos fiéis ao acontecimento, que constroem com suas ações o após-acontecimento, mas há também os sujeitos reativos e os obscuros (BADIOU, 2008, p.72), os quais tentam desconstruir os efeitos do acontecimento na extensidade, se opondo a ele (ver também PRAD0, 2016).

Poderíamos pensar aqui em uma narrativa do acontecimento, feita a posteriori, desde sua emergência (assomo), posterior tentativa de modulação até a constituição do novo estado, com novos regimes de sociabilidade e interação.

0 acontecimento, de certo modo, destitui os

Este texto foi originalmente apresentado no GT Comunicação e Sociabilidade, no XXV Encontro Anual da Compós, na Universidade Federal de Goiás, em junho de 2016. Projeto financiado com bolsa de produtividade do CNPq.

Nossa polêmica aqui se refere a concepções como a ação comunicativa, de Habermas (2012), ou a comunicação como acontecimento de Marcondes Filho, entre outras. Diz este último: "Uma comunicação densa está próxima da arte, ambas como formas de apreensão sensível do mundo. Mais do que a arte, a comunicação se realiza também no plano da interação entre duas pessoas, nos diálogos coletivos onde esse novo tem chance de aparecer, onde 0 acontecimento provoca o pensamento, força-0, onde a incomunicabilidade é trincada e criam-se espaços de interpenetração" (2010, p.23).

A tensividade é acolhida como "lugar imaginário em que a intensidade - ou seja, os estados de alma, o sensível - e a extensidade - isto é, os estados de coisas, o inteligível - unem-se uma à outra". Essa junção define o espaço tensivo "de recepção e qualificação para as grandezas que têm acesso ao campo de presença” (ZILBERBERG, 2011, p.66). Cada grandeza entra nesse espaço, portanto, qualificada em termos de intensidade e extensidade, mas há uma "autoridade do sensível sobre o inteligível" (idem), ou seja, da apreensão sensível dos estados de coisas do mundo. Essas grandezas sofrem gradações, em que 0 sentido sofre modulações. 0 que interessa é tratar cada grandeza de modo a verificar os movimentos de ascendência e descendência no contínuo de seu desenvolvimento, com os respectivos aumentos e diminuições de intensidade. Valência é dada em um nível de pré-sentido, antes que os valores se afirmem. Para Zilberberg, o valor é a "associação de uma valência intensiva com uma valência extensiva" (idem, p.67). Assim, uma grandeza "penetra no campo de presença proporcionalmente à quantidade de impacto e irrupção que traz em si" (idem). Em termos de intensidade, isso pode ser menos ou mais impactante, menos ou mais tênue. Em termos de extensidade, isso pode ser menos ou mais concentrado e mais ou menos difuso. 
sujeitos, pensando-se aqui sujeito como aquele que responde aos discursos, às interpelações, cuja resposta não é apenas a de uma boca falante, mas de um corpo pulsante, palco das pulsões. Como afirma Zilberberg, 0 acontecimento desapropria o sujeito de suas competências modais, como se aquele sujeito que respondia aos discursos dos estados anteriores ao acontecimento não mais pudesse proceder doravante a partir das mesmas formas e dos mesmos afetos. Pensamos aqui 0 sujeito não como um núcleo de consciência que se reforma e se transforma no acontecimento, mas como aquele que emerge a partir dele, criando novas respostas, novos discursos, novas formas de vida. 0 sujeito emerge com 0 acontecimento, na medida em que a ele se torna fiel, na medida em que nasce com essa fidelidade, emerge com essa protensividade originária. Esse tornar-se fiel não se dá frente a um discurso preexistente, mas a algo ligado à intensidade que rompeu com os estados anteriores e inaugura novos discursos, a partir de uma nova economia libidinal, em seu correspondente circuito de afetos (SAFATLE, 2015). 0 acontecimento convida à ação. Como afirma Zilberberg, "do ponto de vista valencial, o acontecimento, por ser portador do impacto, manifesta enquanto tal que o sujeito trocou (...) 0 universo da medida pelo da desmedida" (idem, p. 163). A rigor, é preciso ressaltar, não há troca, mas fim de alguns sujeitos, nascimento de outros. É essa desmedida, essa descontinuidade, que abre o mundo aos devires. Entretanto, a separação que Zilberberg faz do ponto de vista do sujeito, entre sofrer na intensidade do acontecimento e agir na extensividade, após 0 acontecimento, não nos convém, já que, para nós, no acontecimento o sujeito de estado é destituído e 0 acontecimento rompe com a temporalidade do estado anterior, e novos sujeitos podem advir com 0 acontecimento, mas não são mais os mesmos sujeitos ${ }^{4}$. Assim, o sujeito surge com 0 acontecimento, não sofre com ele.

Diríamos que há aí a configuração de duas políticas/estesias possíveis: uma, que privilegia a transformação trazida pelo acontecimento e outra que enfatiza a reforma na extensidade. Seguimos aqui mais a Badiou que a Zilberberg, pois em Badiou a extensividade não é pensada, após o acontecimento, como reparadora. Para Zilberberg, no calor do acontecimento sincrético, com sua intensidade máxima, a afetividade está em seu auge e a legibilidade é nula, não havendo discursos que nesse primeiro momento deem conta do acontecimento. Porém,

Logo em seguida, conforme evolui 0 amortecimento das valências afetantes, 0 acontecimento enquanto tal cessa de obnubilar, de obsedar, de monopolizar, de saturar o campo de presença e, em virtude da modulação diminutiva das valências, o sujeito consegue progressivamente, por si próprio ou com auxílio, reconfigurar o conteúdo semântico do acontecimento em estado, isto é, resolver os sincretismos intensivo e extensivo que 0 discurso projeta (idem, p.169). 
Na visão de acontecimento de Badiou, não há uma retomada, implícita no trecho anterior, em que Zilberberg fala em "reconfiguração", como se com 0 acontecimento algo tivesse sido perdido e devesse ser recuperado após a aclimatação às consequências do acontecimento. Para Badiou, a ruptura do estado anterior tem um saldo positivo, e os sujeitos fiéis nisso apostam. 0 que isso significa? Aquilo que no estado de coisas caracterizado pela representação anterior era injusto, repressivo, injurioso, etc, encontra no acontecimento a emergência que permite vislumbrar uma mudança, entendida por Badiou como singularidade, a qual traz uma potência de existência máxima, inaugurando uma nova temporalidade. Se houver sujeitos nascidos com 0 acontecimento, os quais, efetivamente, coloquem seus corpos a serviço das consequências afetivas transformadoras, então um novo processo de verdade se inicia e novas formas de discurso e de comunicação se instauram. Nesse sentido, não há reconfiguração, mas emergência do novo.

Ao estudar as dinâmicas intensivas e extensivas que 0 acontecimento faz vibrar, Zilberberg apresenta, no primeiro caso, 0 andamento e a tonicidade e, no segundo, a temporalidade e a espacialidade (idem, p. 170). Ao sobrevir, o acontecimento se dá em um andamento vivo, vibrátil, brusco, intenso. Há aí a emergência de algo surpreendente, desmedido e que devasta, retira da ordem cotidiana, enfrentando a tendência de melancolização por parte do poder (BUTLER, 2001, p. 147). Diríamos que 0 acontecimento retira da melancolia um sujeito acoplado a discursos anteriores que 0 aprisionavam em um corpo doloroso. Algo, diz Zilberberg, no acontecimento transtorna 0 sujeito. Já o dissemos: mais que transtorna, destitui, provocando "desorientação modal" (idem, p.171). É por essa razão que, para esse autor, o sujeito fica estupefato e cessa de agir, restando-lhe apenas o sofrer. Preferimos, com Badiou, dizer que quem sofre é a vítima e, no acontecimento, se trata, ao invés, de uma dimensão aberta de infinito, e, portanto, aqui cabe mais afirmar paixões e afetos da alegria, da intensidade ${ }^{5} \mathrm{e}$, portanto, paixões não de liquidação da falta, mas paixões complexas que abrem para os devires. Para Deleuze, "sobre as linhas de fuga, só pode haver uma coisa, a experimentação da vida" (DELEUZE, 1998, p. 61). 0 acontecimento abre não apenas estados de coisas, como diz Zilberberg, mas também linhas de fuga para os devires.

Ocorre com 0 acontecimento uma fulminação da temporalidade: "a recomposição da temporalidade está condicionada à desaceleração e à atomização, ou seja, ao retorno àquela atitude que 0 acontecimento suspendeu momentaneamente" (idem, p. 171). Conforme Zilberberg, o sujeito (aqui comportado demais para nossos propósitos) "almeja reaver pouco a pouco o controle e 0 
domínio da duração, sentir-se novamente capaz de comandar a temporalidade fórica a seu belprazer" (idem). Em termos da visão badiouana, não se trata de recuperar a duração, mas de repensar a temporalidade, a historicidade, dentro da perspectiva do novo processo de verdade implantado a partir do acontecimento. 0 acontecimento se abre para uma justiça que não se reduz a regras de um funcionamento condominial ${ }^{6}$, em que quem gerencia é 0 síndico gestor. No acontecimento, como sustenta Derrida, dá-se um "messianismo desértico (sem conteúdo e sem messias identificáveis)":

Um deserto sinalizando para o outro, deserto abissal e caótico, se o caos descreve primeiramente a imensidão, a desmesura, a desproporção no escancaramento de uma boca aberta - na espera ou na chamada do que denominamos aqui, sem saber, o messianismo: a vinda do outro, a singularidade absoluta e inantecipável do que chega como justiça. Esse messiânico, acreditamos que ele permanece uma marca indelével - que não se pode nem deve apagar - da herança de Marx, e sem dúvida do herdeiro, da experiência da herança em geral. Sem o que reduzir-se-ia a acontecimentalidade do acontecimento, a singularidade e a alteridade do outro (DERRIDA, 1994, p. 47).

\section{Eu S/A}

Uma das partes a participar dessas interações, as quais disputam sentidos, menos ou mais prenhes de conflitos, é constituída pelas máquinas de expressão que, guiadas sobretudo pelos objetivos de controle sistêmico (maximização de efeitos de audiência, aumento de lucros, influência e poder), a partir de um sensoriamento do ambiente, buscam produzir sujeitos ligados ao que Safatle chama de "figura atual do homem", que nós temos caracterizado como o Eu S/A, o sujeito empreendedor de si mesmo, construído como um microempreendimento neoliberal de si, um tipo de sujeito possuidor de um si próprio inflado no âmbito do capitalismo globalizado (ver PRADO, 2013; FREIRE FILHO, 2010; 2011).

A questão é que 0 agente, em sua formação na infância, é constituído a partir de discursos em uma fase em que não pode argumentar com eles, tendo desde cedo se submetido aos mecanismos de poder, como afirma Butler (2001, p.17). Dessa experiência afetiva primária poderão emergir vários tipos de sujeitos, em sua relação com os acontecimentos, mas isso depende dos modos pelos quais o sujeito buscou e conseguiu reconhecimento e de sua relação concreta com os poderes e biopoderes em situação. Daí a importância da teoria do reconhecimento na formação do sujeito. 0 sujeito, primordialmente, se constituiu a partir de experiências de sofrimento de determinação? Teve experiências positivas de indeterminação? Como ele se relaciona com um reconhecimento e 
com normas do poder pastoral em vigor que não passe pela construção de uma figura do tipo Eu S/A? Como ele enfrenta os regimes de verdade aos quais está em cada situação submetido? Em que sentido ele tem condições de se pensar a partir da despossessão de si? ${ }^{7}$ Dunker explica que 0 sofrimento deve obedecer a três condições (idem, p. 219): a) deve ser pensado a partir de uma teoria do reconhecimento, ou seja, todo sofrimento "contém uma demanda de reconhecimento e responde a uma política de identificação"; b) deve ser estruturado como uma narrativa (ou seja, "como trabalho de linguagem que contorna um objeto, conferindo-lhe uma 'estrutura de ficção"'); c) envolve uma experiência de indeterminação.

Essa concepção de sujeito em que ele não é mais pensado a partir da matriz neoliberal do Eu S/A, segundo a qual possui atributos e predicados que moldam méritos e realizações, vistos como propriedades, conecta com a obra de Judith Butler, em que o reconhecimento é ancorado em uma política pensada para "trazer à vida social a potência de um horizonte antipredicativo" (SAFATLE, 2015, p.30). 0 afeto central aqui considerado é o desamparo freudiano, em que o sujeito não se sustenta em determinações, mas se abre a uma afetividade "que tem a força de constituir vínculos a partir do que me despossui de minhas determinações e predicações, por isso afecção do que se desdobra como vínculo inconsciente" (idem, p.32). 0 modelo de comunicação é, nesse caso, não mais o de cooperação intersubjetiva, do contrato, do ajustamento, mas aquele ligado a

modos não intersubjetivos de reconhecimento, em que as figuras do contrato das trocas recíprocas, do consentimento consciente ou da afirmação identitária de si saem de cena para compreendermos melhor como o desamparo, entendido como afeto, pode criar relações. 0 amor é, segundo Lacan, uma relação que nos desampara, mas que nos recria (idem, p. 33).

Em Butler, a teoria de gênero sai do trilho da produção de identidades, tornando-se uma:

astuta teoria de como, através da experiência de algo no interior da experiência sexual que não se submete integralmente às normas $\mathrm{e}$ identidades, descubro que ter um gênero é um 'modo de ser despossuído', de abrir o desejo para aquilo que me desfaz a partir da relação ao outro (SAFATLE in BUTLER, 2015, p. 175).

As normas e os regimes de verdade em vigor no capitalismo globalizado definem figuras valorizadas do Eu S/A, afetivamente investidas, fornecendo os quadros de referência a partir dos quais o reconhecimento dos sujeitos pode se dar. Não pensamos esses sujeitos como essencialistas/ essencializados, pois eles não preexistem aos discursos, como já dissemos: vão se constituindo na medida em que a cada momento respondem aos discursos e aos afetos que os solicitam, a 
partir de uma história de respostas anteriores, incorporadas no corpo, encarnadas. 0 corpo é uma superfície de tensões e pulsões em que emergem esses sujeitos afetados.

0 quadro de reconhecimento não é invariável, segundo Butler (2015, p.34), mas é em relação a tais enquadramentos que 0 sujeito terá de se fazer, se refazer, se destituir e permitir que 0 corpo suporte novos sujeitos acontecimentais, contestando e transformando essas normas, os nomes e os conjuntos/representações que dão identidade às coisas e aos seres. A comunicação nesse nível dos enquadramentos e das normas é, conforme Marcondes Filho (2010, p.22), trivial, conservadora, operando dentro do que Landowski chama de regime de programação ou de manipulação (2014, p.21). Ela visa reproduzir 0 mundo objetivo. Em termos da semiótica tensiva, estamos aqui no domínio da extensividade, não da intensividade. Os afetos nesse nível da comunicação são extensivos, pois o actante segue percursos (sucessão de estados passionais) moderados e modalizados a partir de programas do equilíbrio e da estabilidade.

\section{Do estrutural ao cultural: o sujeito em ricochete}

De acordo com Butler, há uma diferença entre um relato estrutural e um cultural sobre a performatividade, que ela entende como "função de postulação (positing) da linguagem" (BUTLER et allii, 2000, p.28). Para ela

\begin{abstract}
A performance de gênero cria a ilusão de uma substancialidade anterior ou primeira - um self nucleado generificado - e constrói os efeitos do ritual performativo de gênero como emanações necessárias ou consequências desta substância primeira. Mas enquanto Žižek isola as características estruturais da postulação linguística e oferece exemplos culturais para ilustrar esta verdade estrutural, estou mais preocupada em repensar a performatividade como ritual cultural, como reiteração de normas culturais, como habitus do corpo em que as dimensões sociais e estruturais do significado não são enfim separáveis (idem, p.29).Para tanto, atravessaremos tal estrutura: a) pelas análises psicanalíticas de Butler, com a entrada em cena do inconsciente e das pulsões, ligadas ao poder e à performatividade da linguagem, e b) pela tematização do circuito dos afetos em Safatle, também ancorado na psicanálise, que pergunta como isso implica em enfrentar a economia libidinal e 0 circuito dos afetos que confirmam as políticas e os regimes de visibilidade e de verdade enfrentados. Pois nosso interesse não está apenas em mapear os percursos passionais estruturais dos textos, em que os sujeitos narrativos buscam afetivamente objetos de valor e se ligam a outros sujeitos, através de percursos modais e passionais, nos quais confiam para buscar coisas ou atuar em processos conjuntos, mas em entender como o poder constrói sujeitos que, desde crianças, se formam em discursos afetivamente investidos que não dominam, e reiteradamente a eles se submetem. Além disso, interessa perguntar como os sujeitos investidos por esses poderes podem subverter essa dominação.
\end{abstract}

a) Comecemos com Butler. 0 poder aparenta ser externo: "pressionando o sujeito à subordinação, assume uma forma psíquica" (BUTLER, 2001, p. 13), a qual constitui sua identidade. 0 poder melancoliza. Para Safatle:

A hipótese de Judith Butler consistirá em mostrar como a força da submissão dos sujeitos, seja às identidades de gênero pensadas em 
uma matriz estável e insuperável, seja à forma geral da identidade, é indissociável dos usos da melancolia. 0 poder age produzindo em nós melancolia, fazendo-nos ocupar uma posição necessariamente melancólica. Podemos mesmo dizer que o poder nos melancoliza e é desta forma que ele nos submete. (...) A melancolia aparece como uma das múltiplas formas, mas a mais paralisante, de aceitar ser habitado por um discurso que, ao mesmo tempo, não é meu mas me constitui (SAFATLE in BUTLER, 2015, p. 190).

Butler, no livro citado (2001), trabalhará 0 dar-se volta do sujeito quando este se vira para responder a uma interpelação vinda da autoridade, do poder, como no exemplo de Althusser, em que o policial grita: "Alto lá!" e nesse momento em que a voz autoritária interpela 0 indivíduo caminhante, cria-se 0 sujeito, quando ele se volta para responder ao policial. Esse modelo será continuado por Foucault. Butler pergunta como o poder forma o sujeito, como esse 0 acolhe, apontando aí um paradoxo, pois nos vemos obrigados a nos referir a algo que ainda não existe: "tentamos dar conta de como nasce 0 sujeito mediante uma figura que provoca a suspensão de nossas certezas ontológicas" (idem, p.14). Essa volta do sujeito é tropológica, resultando daí que a melancolia "participa do mesmo mecanismo que descreve, produzindo topografias psíquicas que são claramente tropológicas" (idem, p.15). Assim,

não se trata somente de que a função do tropo seja a geração (do sujeito), mas de que a descrição desta parece exigir a utilização de tropos, uma operação de linguagem irredutivelmente mimética e performativa, que reflete e ao mesmo tempo institui a generatividade que se pro- põe a explicar (ibidem).Para Butler, a interpelação é a produção discursiva do sujeito em uma situação comunicativa, pois tem lugar nesse intercâmbio "pelo qual o reconhecimento é oferecido e aceito. A questão é: por que esse sujeito se volta para responder na direção da voz autoritária da lei? Que afetos acompanham essa voz interpeladora? Esse é um sujeito culpável? Que afetos se ligam à resposta do sujeito? Ele se instaura com medo da polícia, porque já ouviu relatos de agressões a cidadãos? Como o poder lida com tais sujeitos? 0 poder goza ao bater neles? Ao trancafiar e punir (lembramos aqui do filme 0 decálogo, episódio "Não matarás", de Kieslowski)? Há aí uma consciência em que se dá o funcionamento psíquico da norma reguladora? Em torno dessa questão gira esse livro de Butler (2001). Essa voz autoritária tem poder performativo, pois, ao dizer, ela faz, ela faz fazer, ela modaliza. E aí está envolvido um percurso passional, pois 0 sujeito se volta para o policial com temor, com culpa, inseguro ou com raiva, caso esteja em uma passeata e 0 governo coloca a polícia para jogar bombas de efeito moral.

Segundo Salih, "Butler argumenta que, como não existe nenhuma identidade social sem sujeição, o sujeito está passionalmente preso à lei ou à autoridade que o sujeita" (SALIH, 2015, p.165; BUTLER, 2001, p.17). Conforme Butler, o sujeito "seria o efeito do poder em dobra, em ricochete (in recoil) (ibidem). 0 sujeito é ao mesmo tempo formado e subordinado. Há aí uma ambivalência, que permite a Butler afirmar que 0 sujeito emerge ao mesmo tempo que o inconsciente.

A definição foucaultiana da sujeição como a simultânea subordinação e formação do sujeito assume um valor psicanalítico concreto ao considerarmos que nenhum sujeito emerge sem um vínculo apaixonado com aqueles de quem depende de maneira essencial (idem, p. 18). En- 
tretanto, existe aí um potencial de agência, ou seja, um potencial da psique de "fazer o poder se voltar contra si mesmo" (idem, p.166). Em nossos termos, a agência se coloca a partir de um acontecimento, ao permitir confronto com o poder e transformação do estado de coisas.

Pergunta Butler: como a forma psíquica se constitui a partir das estruturas de poder? A relação com o poder é ambivalente: 0 sujeito não existe sem o poder, mas 0 excede, pode ser agente, subvertê-lo. Até que ponto os afetos ligados à sujeição são mais poderosos que os da alegria que brotam no acontecimento? 0 sujeito está em uma posição paradoxal, pois está preso à sujeição e esta lhe causa algum tipo de prazer: "Butler pressupõe que os sujeitos querem desejar; no entanto, o objeto de seu desejo é precisamente aquilo que os impediria de querer" (SALIH, 2015, p.173). Como romper com o prazer da pulsão de morte, que desacontecimentaliza a vida??. Nem 0 corpo nem a psique preexistem aos discursos de poder. Eles são formações discursivas que emergem simultaneamente através da sublimação do corpo na alma. 'Sublimação' é um termo psicanalítico que descreve a transformação ou o desvio do instinto sexual para atividades 'culturais' ou 'morais'. (...) A sublimação do corpo na alma ou psique deixa para trás um 'remanescente corporal', que excede 0 processo de normalização e sobrevive como aquilo que ela chama de 'uma espécie de perda constitutiva' (idem, p. 176).
Assim, o corpo não é lugar de uma construção, mas: o sujeito vem a existir quando seu corpo é alvo de uma ação e é destruído (presumivelmente pelo discurso?), o que significa que essa é uma destruição produtiva ou, talvez, uma suprassunção ou Aufhebung, uma vez que tanto o corpo quanto a psique são simultaneamente formados e destruídos no interior de estruturas discursivas (SALIH, idem, p. 176). Ao sermos chamados por um nome injurioso, diz Butler, isso nos dá uma existência social, pois o narcisismo se ocupa de qualquer termo que confira existência, então "sou levada a abraçar quaisquer termos que me injuriam porque eles me constituem socialmente" (SALIH, idem, 177). 0 poder deve ser reiterado, e "0 sujeito é precisamente 0 lugar desta reiteração, que nunca é uma repetição meramente mecânica" (idem, p. 27). Desta forma, uma estrutura tabelar das paixões é apenas um ponto de partida, mas não deve nos guiar peremptoriamente, porque aí se perderia a dinâmica inconsciente que faz oscilar tensivamente o sujeito entre submissão e agenciamento acontecimental. 0 dilema assim se coloca para Butler: "como adotar uma atitude de oposição frente ao poder, mesmo reconhecendo que toda oposição está comprometida com 0 mesmo poder a que se opõe?" (ibidem). Que afetos me ligam ao poder a que me coloco como submisso e que afetos despertam nesse 
lançamento para devires agenciadores? Isso

coloca um sério problema para a teoria política: ou bem se considera que as formas de dominação capitalista ou simbólica são tais que nossos atos estão sempre já ‘domesticados' a priori, ou bem se oferece uma série de ideias generalizadas e atemporais sobre 0 caráter aporético de todos os movimentos dirigidos ao futuro. Sugiro que a cumplicidade primária com a subordinação não conduz forçosamente a nenhuma conclusão histórica ou lógica, mas que abre algumas possibilidades tentativas. 0 fato de que a potência esteja comprometida na subordinação não é sinal de uma inevitável contradição interna no núcleo do sujeito, nem, por conseguinte, uma prova adicional de seu caráter pernicioso ou obsoleto. Mas tampouco permite restaurar uma visão purista do sujeito derivada de visões liberais-humanistas clássicas, onde a potência aparece, sempre e exclusivamente, em oposição ao poder. A primeira dessas visões caracteriza as formas politicamente farisaicas de fatalismo; a segunda, as formas ingênuas de otimismo político (idem, p. 28). Aqui, a visão de crítica de Butler se coloca, portanto, contra teorias críticas que apresentam uma descrição apocalíptica do mundo cibercultural e globalizado da atualidade. Sim, nossos atos estão domesticados, pois fomos formados na submissão a formas modalizadas do Eu S/A, mas é preciso pensar a abertura acontecimental para novos processos de verdade e para a emergência de novos sujeitos agenciadores e, a partir dessa abertura, inaugurar novas linhas de fuga, até que, eventualmente, emerja 0 acontecimento. De um lado, é preciso romper com o fatalismo, de outro com a visão clássica do sujeito centrado em atributos de identidade (sucesso, self autocentrado, etc.), trabalhando na tensão entre submissão e agenciamento. A análise deve trabalhar nessa dinâmica tensiva complexa. Tanto Freud como Nietzsche, na visão de Butler, explicam a constituição da consciência como efeito de uma proibição internalizada:

a proibição da ação ou da expressão faz a pulsão voltar-se para si mesma, constituindo um âmbito interno, que é a condição da introspecção e reflexividade. A pulsão que se volta sobre si mesma se converte em condição catalizadora da formação do sujeito; trata-se de um desejo primário dobrado sobre si que aparece também esboçado na visão da consciência infeliz de Hegel (BUTLER, idem, p. 33).

\section{Melancolia}

A incorporação melancólica, nos lembra Butler, é justamente um modo de 0 sujeito se desligar do objeto perdido, incorporando-o no Eu. Desde cedo, toda a formação do sujeito está investida pelas paixões e pelos afetos. Como? Ele não se desliga definitivamente do objeto perdido, mas produz uma identificação melancólica, que "permite a perda do objeto no mundo externo", ao mesmo tempo em que oferece um modo de preservá-lo como parte do eu e, por conseguinte, de evitar que a perda seja total. Aqui vemos que se desligar do objeto significa, paradoxalmente, não seu abandono total, mas a transformação de seu 
estatuto externo em interno. A renúncia ao objeto se torna possível somente sob a condição de uma internalização melancólica ou, o que para nossos propósitos pode ser ainda mais importante, uma incorporação melancólica (BUTLER, 2011, p.149).

A internalização preserva a perda na psique, ao mesmo tempo em que a nega. A melancolia é um circuito produzido e faz parte, portanto, do funcionamento do poder regulador (idem, p. 158, grifo nosso). Para Butler, se a melancolia designa um âmbito de vinculações que não aparece explicitamente como objeto do discurso, então erode a operação de linguagem pela qual esta não apenas postula objetos, mas também os regula e normaliza ao postulá-los. Enquanto a melancolia parece ser, em princípio, uma forma de contenção, um modo de internalizar um vínculo que está excluído do mundo, também estabelece as condições psíquicas para ver que '0 mundo' se organiza de maneira contingente através de certo tipo de repúdios (idem, p.158).

Essa dobra do sujeito sobre si, esse recolhimento ancorado em um repúdio, na medida em que faz com que o sujeito se constitua e ao mesmo tempo se sujeite ao poder está afetivamente carregada, e a economia libidinal e seu circuito de afetos precisam ser investigados para que a teoria social e política possa pensar a forma da agência pós-acontecimental (embora não se possa planejá-la), bem como entender o quadro dos afetos possíveis na potência de existência dada nas singularidades emergentes após a intensidade do acontecimento. b) É importante pensar, portanto, a política que altera os regimes de sociabilidade e de visibilidade, ou seja, os regimes e dispositivos que regulam as formas de ver, de ser vista $\mathrm{e}$ de valorar positiva ou negativamente essas imagens e interações, bem como o circuito dos afetos. A tensão do acontecimento busca romper com a formação de sujeitos constituídos pela identidade encarnada no $\mathrm{Eu}$ S/A, o qual vive em condomínios, assegurado contra a invasão dos Outros, com medo de perder seu mundo protegido e securitizado. De acordo com Safatle, o medo como afeto político (...) tende a construir a imagem da sociedade como corpo tendencialmente paranoico, preso à lógica securitária de que deve se imunizar contra toda violência que coloca em risco o princípio unitário da vida social (SAFATLE, 2015, p. 24). Não é o medo 0 afeto sobredeterminante único, pois dá-se também a busca de alívio, tranquilidade, desafogo de viver dentro do condomínio, de ter uma identidade protegida de Eu S/A, que tem atributos de sucesso e capital. É claro que, ao lado desses afetos, há o medo do Outro extorquir um gozo que seria 0 meu, de me privar da parcela de gozo que penso minha. Sob a perspectiva de uma política rumo a uma democracia radical, não se trata de buscar uma figura de Eu S/A, com medo do Outro, vivendo em um alívio tíbio e ligeiramente animado, muitas vezes adrenalinadamente regado a fast sexo, a escaladas em academias e raves, nem na esperança que nos tira do instante, ou seja, adia nosso compromisso com o messiânico de que falava Derrida (já citado). 
A estratégia agenciadora nos leva a perguntar:

"Qual corporeidade social pode ser produzida por um circuito de afetos baseado no desamparo" (idem, p.25), que cria vínculos de despossessão? Como vimos, Safatle propõe o desamparo como afeto primordial, para saída do percurso dominante do medo, mas é preciso salientar que nem o medo é o único afeto do poder, nem o desamparo, 0 único afeto revolucionário. Na intensidade pós-acontecimental, em que os regimes de sociabilidade e de visibilidade podem ser transformados, muitos afetos podem acompanhar os agenciamentos dos sujeitos fiéis, como alegria, desapego, cuidado com o outro, satisfação, felicidade, distensão, tensão, amor, afeto, amizade; por outro lado, ao enfrentar os sujeitos obscuros e reativos, poderão surgir paixões como ódio, fúria, raiva, irritação, desânimo. Não há reconhecimento sem luta por ele, imersa em afetos variados.

É preciso ter em conta que Safatle enfatiza 0 desamparo, na medida em que esse afeto se liga à possibilidade de se pensar um eu não idêntico. Se 0 eu pós-acontecimental, o sujeito fiel, se guiar pela lógica da identidade, retornaremos a um estado pré-acontecimental. Safatle afirma:

Estar desamparado é deixar-se abrir a um afeto que me despossui dos predicados que me identificam. Por isso, afeto que me confronta com uma impotência que é na verdade forma de expressão do desabamento de potências que produzem sempre os mesmos atos, os mesmos agentes. Um corpo político produzido pelo desamparo é um corpo em contínua despossessão e des-identificação de suas determinações. Corpo sem eu comum e unicidade, atravessado por antagonismos e marcado por contingências que desorganizam normatividades impulsionando as formas em direção a situações impredicadas. Por isso, 0 desamparado produz corpos em errância, corpos desprovidos da capacidade de estabilizar 0 movimento próprio aos sujeitos através de um processo de inscrição de partes em uma totalidade (idem, p. 26).

Para pensarmos esse eu despossuído, a obra de Butler é fundamental. Para tanto, é preciso romper com uma dimensão antropológica comunicativa altamente normativa, pois construída a partir de categorias de teor psicológico como 'identidade pessoal' e 'personalidade'. Nessa via, as demandas por reconhecimento não mais seriam compreendidas como "potencialidades capazes de permitir o desenvolvimento de predicações da pessoa individualizada" (idem, p. 28). A proposta de Safatle, portanto, de um modo de reconhecimento antipredicativo nos leva a pensar em uma outra comunicação, não mais baseada no acordo de pessoas em contrato, mas em uma relação feita a partir da diferença:

Contrariamente à ficção filosófica do amor como uma espécie de afecção que, através do reforço de estruturas cooperativas e de afirmação mútua de interesses particulares, nos leva a construir relações sob a forma do contrato tácito entre pessoas que se afetam de forma consensual e consentida, a reflexão psicanalítica sobre 0 amor proposta por Lacan nos permite pensar modos não intersubjetivos de reconhecimento, no qual as figuras do contrato das trocas recíprocas, do consentimento consciente ou da afirmação identitária de si saem de cena para compreendermos melhor como o desamparo, 
entendido como afeto, pode criar relações. 0 amor é, segundo Lacan, uma relação que nos desampara, mas que nos recria. A reflexão sobre 0 amor demonstra seu interesse político na medida em que abre a compreensão para formas de reconhecimento entre sujeitos que, ao menos por um momento, deixam de querer ser determinados como pessoas individualizadas (idem, p. 32/33).

\section{Referências}

BADIOU, A. Lógicas de los mundos. Buenos Aires, Manantial, 2008.

BARROS, D. L. P. Paixões e apaixonados: exame semiótico de alguns percursos. In: Cruzeiro Semiótico, n.11/12, pp. 60-73. Lisboa: Associação Portuguesa de Semiótica, 1990.

BUTLER, J. Relatar a si mesmo. Belo Horizonte: Autêntica, 2015.

. Mecanismos psíquicos del poder.

Madrid: Ediciones Cátedra, 2001.

BUTLER, J.; ŽIŽEK, S.; LACLAU. E. Contingency, hegemony, universality. London: Verso, 2000.

DELEUZE, G.; PARNET, C. Diálogos. São Paulo: Escuta, 1998.

DERRIDA, J. Espectros de Marx. Rio de Janeiro: Relume-Dumará, 1994.

DUNKER, C. I. L. Mal-estar, sofrimento e sintoma. São Paulo: Boitempo, 2015.

FREIRE FILHO, J.; PINTO COELHO, M.G. (org.) A

promoção do capital humano. Porto Alegre: Sulina, 2011.

. (org.) Ser feliz hoje. Rio de

Janeiro: Globo Universidade; FGV, 2010.

HABERMAS, J. Teoria do agir comunicativo. 2 vols.

São Paulo: Martins Fontes, 2012.
LANDOWSKI, E. Interações arriscadas. São Paulo:

Estação das Letras e Cores, 2014.

MARCONDES FILHO, C. 0 princípio da razão

durante. Nova teoria da comunicação III - Tomo V. São Paulo: Paulus, 2010.

NANCY, J.-L. Ser singular plural. Madrid: Arena Libros, 2006.

PRAD0, J.L.A. Comunicação e reinvenção acontecimental da política. In: Reinvenção

comunicacional da política. Brasília: Compós, 2016. . Comunicação como epistemologia

do sul: do reconhecimento à emergência do acontecimento. In: Matrizes. V.9, n.2, jul./dez., pp.109125. São Paulo: ECA-USP, 2015. . Convocações biopolíticas dos

dispositivos comunicacionais. São Paulo: Educ, 2013.

SAFATLE, V. 0 circuito dos afetos. São Paulo: Cosac Naify, 2015.

SALIH, S. Judith Butler e a teoria queer. Belo Horizonte: Autêntica, 2012.

ZILBERBERG, C. Elementos de semiótica tensiva. São Paulo: Ateliê Editorial, 2011. 


\section{Tense recognition,} inaugural event: towards another communication

\section{Reconocimiento tenso,} acontecimiento inaugural: en la dirección de otra comunicación

\section{Abstract}

Starting from a theory of event, we seek to envision communication as the circulation of portents in an affectively invested tensive field in which individuals emerge that are loyal to the process of truth brought about by the event. Here, tensivity is seen in light of Zilberberg, the theory of events in light of Badiou, and the formation of the individual, subjected to power but capable of agency, in light of Butler and Safatle, who in turn propose powerlessness as a fundamental affect. Communication is thus seen based on the theory of events of a political nature, which can thematize the transformation of the circuit of affects, and hence, the emergence of new sociabilities.

\section{Keywords}

Theory of event; affect; politics.

\section{Resumen}

Con base en una teoría del acontecimiento, procuramos pensar la comunicación como circulación de marcas en un campo tensivo, investido afectivamente, donde los sujetos emergen al ser fieles al proceso de verdad instaurado con el acontecimiento. Se piensa la tensividad con Zilberberg, la teoría del acontecimiento con Badiou, la formación del sujeto - sometido al poder, pero capaz de agencia -, con Butler y Safatle, quien a su vez plantea el desvalimiento como afecto fundamental. Por ende, la comunicación se plantea partiendo de la teoría del acontecimiento, con un cuño político que permite tematizar la transformación del circuito de los afectos y así también la emergencia de nuevas sociabilidades.

\section{Palabras clave}

Teoría del acontecimiento; tensividad; afecto; política; sujeto no idéntico. 


\section{Expediente}

A revista E-Compós é a publicação científica em formato eletrônico da Associação Nacional dos Programas de Pós-Graduação em Comunicação (Compós). Lançada em 2004, tem como principal finalidade difundir a produção acadêmica de pesquisadores da área de Comunicação, inseridos em instituições do Brasil e do exterior.

\section{E-COMPÓS I www.e-compos.org.br I E-ISSN 1808-2599}

Revista da Associação Nacional dos Programas de Pós-Graduação em Comunicação.

Brasília, v.20, n.1, jan./abr. 2017.

A identificação das edições, a partir de 2008, passa a ser volume anual com três números.

Indexada por Latindex I www.latindex.unam.mx

\section{CONSELHO EDITORIAL}

Alda Cristina Silva da Costa, Universidade Federal do Pará, Brasil Alfredo Luiz Paes de Oliveira Suppia, Universidade Estadual de Campinas, Brasil Álvaro Larangeira, Universidade Tuiuti do Paraná, Brasil Ana Carolina D. Escosteguy, Pontifícia Universidade Católica do Rio Grande do Sul, Brasil Ana Regina Barros Rego Leal, Universidade Federal do Piauí, Brasil Ana Carolina Rocha Pessôa Temer, Universidade Federal de Goiás, Brasil Andrea França, Pontifícia Universidade Católica do Rio de Janeiro, Brasil André Luiz Martins Lemos, Universidade Federal da Bahia, Brasil Angela Cristina Salgueiro Marques, Faculdade Cásper Libero, Brasil Ângela Freire Prysthon, Universidade Federal de Pernambuco, Brasil Antonio Carlos Hohlfeldt, Pontifícia Universidade Católica do Rio Grande do Sul, Brasil Arthur Ituassu, Pontifícia Universidade Católica do Rio de Janeiro, Brasil Bruno Campanella, Universidade Federal Fluminense, Brasil Cláudio Novaes Pinto Coelho, Faculdade Cásper Líbero, Brasil Carlos Eduardo Franciscato, Universidade Federal de Sergipe, Brasil Denise Tavares da Silva, Universidade Federal Fluminense, Brasil Eduardo Vicente, Universidade de São Paulo, Brasil Eliza Bachega Casadei, Escola Superior de Propaganda e Marketing - SP, Brasil Elizabeth Nicolau Saad Corrêa, Universidade de São Paulo, Brasil Erick Felinto de Oliveira, Universidade do Estado do Rio de Janeiro, Brasil Erly Vieira Júnior, Universidade Federal do Espirito Santo, Brasil Francisco de Assis, FIAM-FAAM Centro Universitário, Brasil Francisco Elinaldo Teixeira, Universidade Estadual de Campinas, Brasil Frederico de Mello Brandão Tavares, Universidade Federal de Ouro Preto, Brasil Gabriela Reinaldo, Universidade Federal do Ceará, Brasil Gilson Vieira Monteiro, Universidade Federal do Amazonas, Brasil Gustavo Daudt Fischer, Universidade do Vale do Rio dos Sinos, Brasil Igor Sacramento, Fundação Oswaldo Cruz, Brasil Itania Maria Mota Gomes, Universidade Federal da Bahia, Brasil Jiani Adriana Bonin, Universidade do Vale do Rio dos Sinos, Brasil José Afonso da Silva Junior, Universidade Federal de Pernambuco, Brasil
José Luiz Aidar Prado, Pontifícia Universidade Católica de São Paulo, Brasil Juçara Gorski Brittes, Universidade Federal de Ouro Preto, Brasil Laura Loguercio Cánepa, Universidade Anhembi Morumbi, Brasil Liziane Soares Guazina, Universidade de Brasilia, Brasil Luíza Mônica Assis da Silva, Universidade Católica de Brasília, Brasil Maria Ataide Malcher, Universidade Federal do Pará, Brasil Maria Elisabete Antonioli, Escola Superior de Propaganda e Marketing - SP, Brasil Maria das Graças Pinto Coelho, Universidade Federal do Rio Grande do Norte, Brasil Marcel Vieira Barreto Silva, Universidade Federal da Paraíba, Brasil Marcia Tondato, Escola Superior de Propaganda e Marketing, Brasil Marli Santos, Universidade Metodista de São Paulo, Brasil Márcio Souza Gonçalves, Universidade do Estado do Rio de Janeiro, Brasil Mauricio Mario Monteiro, Universidade Anhembi Morumbi, Brasil Mauricio Ribeiro da Silva, Universidade Paulista, Brasil Mauro de Souza Ventura, Universidade Estadual Paulista, Brasil Mayka Castellano, Universidade Federal Fluminense, Brasil Micael Maiolino Herschmann, Universidade Federal do Rio de Janeiro, Brasil Mozahir Salomão Bruck, Pontifícia Universidade Católica de Minas Gerais, Brasil Nísia Martins Rosario, Universidade Federal do Rio Grande do Sul, Brasil Potiguara Mendes Silveira Jr, Universidade Federal de Juiz de Fora, Brasil Raquel Ritter Longhi, Universidade Federal de Santa Catarina, Brasil Regiane Regina Ribeiro, Universidade Federal do Paraná, Brasil Roberto Elísio dos Santos, Universidade Municipal de São Caetano do Sul, Brasil Rodolfo Rorato Londero, Universidade Estadual de Londrina, Brasil Sérgio Luiz Gadini, Universidade Estadual de Ponta Grossa, Brasil Simone Maria Andrade Pereira de Sá, Universidade Federal Fluminense, Brasil Simone Maria Rocha, Universidade Federal de Minas Gerais, Brasil Suzana Reck Miranda, Universidade Federal de São Carlos, Brasil Tarcyanie Cajueiro Santos, Universidade de Sorocaba, Brasil Tatiana Oliveira Siciliano, Pontifícia Universidade Católica do Rio de Janeiro, Brasil Veneza Mayora Ronsini, Universidade Federal de Santa Maria, Brasil

\section{CONSELHO CIENTÍFICO}

Cristiane Freitas Gutfreind, Pontifícia Universidade Católica do Rio Grande do Sul, Brasil Eduardo Morettin, Universidade de São Paulo, Brasil

Felipe Costa Trotta, Universidade Federal Fluminense, Brasil Irene de Araújo Machado, Universidade de São Paulo, Brasil

\section{COMISSÃO EDITORIAL}

Eduardo Antonio de Jesus, Universidade Federal de Minas Gerais, Brasil Marco Antonio Roxo da Silva, Universidade Federal Fluminense, Brasil Osmar Gonçalves dos Reis Filho, Universidade Federal do Ceará, Brasil

\section{CONSULTORES AD HOC}

Kelly C. de Souza Prudencio, Universidade Federal do Paraná, Brasil Francisco P. Jamil A. Marques, Universidade Federal do Paraná, Brasil Tiago Quiroga F. Neto, Universidade de Brasília, Brasil

\section{EQUIPE TÉCNICA}

ASSISTENTE EDITORIAL Márcio Zanetti Negrini REVISÃO DE TEXTOS Press Revisão EDITORAÇÃO ELETRÔNICA Roka Estúdio IMAGEM DE CAPA Silas de Paula

\section{COMPÓS I www.compos.org.br}

Associação Nacional dos Programas de Pós-Graduação em Comunicação

Presidente

Edson Fernando Dalmonte

Programa de Pós-Graduação em Comunicação

e Cultura Contemporânea - UFBA

edsondalmonte@uol.com.br

Vice-presidente

Cristiane Freitas Gutfreind

Programa de Pós-Graduação em Comunicação Social - PUC-RS cristianefreitas@pucrs.br

Secretário-Geral

Rogério Ferraraz

Programa de Pós-Graduação em Comunicação

Universidade Anhembi Morumbi

rogerioferraraz@anhembimorumbi.edu.br

CONTATO I revistaecompos@gmail.com 